\title{
Epidemiology, Clinico-Pathological Characteristics, and Comorbidities of SARS-CoV-2 infected Pakistani Patients
}

Saadia Omer ${ }^{1,2,3 \#,}$ Muhammad Bilal Sarwar ${ }^{1 \#,}$ Muhammad Roman ${ }^{1}$, Muhammad Usman ${ }^{4}$, Muhammad Alam ${ }^{1}$, Nadeem Afzal ${ }^{1}$, Tanveer Ahmed Qaiser ${ }^{5}$, Muhammad Yasir ${ }^{6}$, Faheem Shahzad $^{1}$, Romeeza Tahir ${ }^{1}$, Saima Ayub $^{2}$, Javid Akram ${ }^{1,}$ Shah Jahan ${ }^{1 *}$

${ }^{1}$ Department of Immunology, University of Health Sciences, Lahore Pakistan.

${ }^{2}$ Institute of Public Health, Lahore Pakistan.

${ }^{3}$ Fatima Jinnah Medical University, Lahore, Pakistan.

${ }^{4}$ Allama Iqbal Medical College, Jinnah Hospital Lahore Pakistan.

${ }^{5}$ Shaheed Zulfiqar Ali Bhutto Medical University, Islamabad

${ }^{6}$ Quadram Institute Bioscience, Norwich Research Park, NR4 7UQ, United Kingdom.

Saadia Omer: saadiaomer@ live.com

Muhammad Bilal Sarwar: bilal.sarwar@cemb.edu.pk

Muhammad Roman: mroman@uhs.edu.pk

Muhammad Usman: m.usmanmukhtar@yahoo.com

Muhammad Alam: alamkhankmu@gmail.com

Javid Akram: jakramaimc@gmail.com

Naveed Afzal, immunology@uhs.edu.pk

Muhammad Yasir: Muhammad.Yasir@quadram.ac.uk

Faheem Shahzad: faheemuhs@edu.pk

Romeeza Tahir: romeeza.tahir@uhs.com

Samia Ayub: drsaimaayub@yahoo.com

Shah Jahan: shahjahan@uhs.edu.pk

*Corresponding author

${ }^{\#}$ Both authors contribute equally

Keywords: SARS-CoV-2, COVID-19, Acute Respiratory Distress Syndrome, Clinico-Pathological characteristics, CT scan, comorbidities, medication, mechanic, non-ICU vs. ICU 


\begin{abstract}
:
SARS-CoV-2 is a causative agent for COVI-19 disease, initially reported from Wuhan, China. Infected Patients experienced mild to severe symptoms, resulting in several fatalities due to a weak understanding of its pathogenesis, which is the same even to date. This cross-sectional study has been designed on four hundred and fifty-two symptomatic, mild-to-moderate, and severe/critical patients to understand the epidemiology and clinical characteristics of COVID-19 patients with their comorbidities and response to treatment. The mean age of studied patients was $(58 \pm 14.42)$ years, and the overall male to female ratio was 61.7 to $38.2 \%$, respectively. $27.3 \%$ of the patients had a history of exposure, $11.9 \%$ travel history, while for $60 \%$ of patients, the source of infection was unknown. The most prevalent signs and symptoms in ICU patients were dry coughs, myalgias, shortness of breath, gastrointestinal discomfort, and abnormal Chest X-ray $(p<0.001)$, along with the high percentage of hypertension $(p=0.007)$ and COPD $(p=0.029)$ as leading comorbidities. Complete Blood Counts indicators were significantly increased in severe patients, while the Coagulation Profile and D-dimer values were significantly higher in mild-tomoderate (non-ICU) patients $(p<0.001)$. Serum Creatinine $\left(1.22\right.$ umole $\left.\mathrm{L}^{-1} ; p=0.016\right)$ and LDH $\left(619 \mathrm{umol} \mathrm{L}^{-1} ; p\right.$ $<0.001)$ indicators were significantly high in non-ICU patients while, raised values of Total Bilirubin $(0.91$ umol L1; $\mathrm{p}=0.054)$, CRP (84.68 mg L-1; $\mathrm{p}=0.001)$ and Ferritin (996.81 $\left.\mathrm{mg} \mathrm{L}^{-1} ; \mathrm{p}<0.001\right)$ were found in ICU patients. Drug Dexamethasone was the leading prescribed and administrated medicine to the COVID-19 patients, followed by Remdesivir, Meropenem, Heparin, and Tocilizumab, respectively. A characteristic pattern of Ground glass opacities (GGO), consolidation, and interlobular septal thickening were prominent in severely infected patients. These findings could be used for future research, control, and prevention of SARS-CoV-2 infected patients.
\end{abstract}

\title{
1. Introduction
}

The novel Coronavirus (2019-nCoV) was first identified, in patients with pneumonia of unknown cause, originating in Wuhan, China, in late December 2019 (Lu, Stratton, and Tang 2020; Zhou et al. 2020). The virus that caused this infection belongs to the Conronaviridae family (Lvov and Alkhovsky 2020). Later, this virus was named "Severe Acute Respiratory Syndrome Coronavirus 2" (SARS-CoV-2) by the World Health Organization (WHO) that caused the coronavirus disease 19 (COVID-19) (WHO 2020). In January 2020, WHO declared the COVID-19 outbreak, a Public Health Emergency of International Concern, and a pandemic in March 2020 (J. Sun et al. 2020). As of September 2021, WHO has reported 228,8076,631 confirmed cases, with more than 4,697,099 deaths attributed to the ongoing COVID-19 pandemic, while Within Southeast Asia, the confirmed cases have risen 42,594,688 (WHO 2021).

In Pakistan, the first confirmed case of COVID-19 was reported on February 26, 2020, and until June 17, 2020, COVID-19 patients were detected in all parts of the country despite the adopted safety measures (Khalid and Ali 2020; Mushtaq et al. 2020). Initially, due to the lack of access to essential healthcare services at the Pak-Iran border, the asymptomatic pilgrims returning from Iran to Pakistan introduced the virus in Pakistan (Javed et al. 2021), and later, over the period, unchecked non-essential international travel to Pakistan has led to its spread in all 
parts of the country (Nawaz et al. 2020). Considering the severity of the pandemic, the Government of Pakistan has established the National Command and Operational Centre (NCOC) to synergize and articulate national efforts against COVID-19 (NCOC 2021b). Measures taken by NCOC to control pandemics were quite effective. NCOC adopted the WHO checklist to exercise travel restrictions, smart lockdowns, workplace hazard controls, and even facility closures to minimize exposure with the carriers (asymptomatic) as preventive measures (NCOC 2021c). As of September 2021, Pakistan's total confirmed COVID count had reached 1,230,238 with 27,374 deaths and 1,140,917 recoveries (NCOC 2021a). Despite the control measures launched into action, the alarming rise in COVID-19 cases and increasing fatalities in the region have raised multiple concerns regarding the infrastructure of our health system and the overwhelming burden placed on it. Understanding the relationship between COVID-19 and epidemiological features like clinicopathological characteristics and treatment available for mild-to-moderate and severe patients is essential to suggest preventive measures. Epidemiological features include age, sex, race, and comorbidities, which are the most studied parameters not only in COVID-19 but also in other infectious diseases (Yang et al., 2020, Sun et al., 2020b, Bi et al., 2020).

Practically most health workers relied upon clinical signs and symptoms, mainly involving the respiratory and digestive system, associated with fever, fatigue, and lab findings such as raised values of IL-6, D-dimer, Procalcitonin, CBC counts, etc. to assess disease prognosis (Grant et al. 2020; Lechien et al. 2020; Tian et al. 2020). SARS-CoV-2 infected patients showed variable symptoms, ranging from mild to severe illness. It primarily affects the pulmonary system producing symptoms like a sore throat, cough, rhinorrhea, nasal congestion, dyspnea, digestive system causing nausea, vomiting, diarrhea, abdominal pain; associated systemic symptoms like fever, headache, myalgia, arthralgia, generalized body ache, and fatigue. It may affect the nervous system, causing atypical clinical findings, such as anosmia, loss of taste, dizziness, and rarely seizure. The most common symptoms seen were fever, dyspnea, myalgia, etc. One in five patients infected with SARS-CoV-2 did not develop noticeable symptoms, acting as a silent carrier, thereby increasing the chances of further progression of SARS-CoV-2 infection and putting old age patients at risk and those with associated comorbidities like Diabetes, Hypertension, COPD, ARDS, IHD, Chronic Liver Disease, Chronic Kidney Disease. Comorbidities and the nature of pathological findings in the organs and tissues are the leading factors that determine the disease severity and outcome (Gu and Korteweg 2007; Mueller, McNamara, and Sinclair 2020)

The mortality ratio of COVID-19 patients depends on viral-host genetic interaction and geographical setting (international and regional spread), as climates differences influence viral transmission via respiratory droplets (Oberemok et al. 2020). Punjab is the largest and most densely populated province of Pakistan, has a population of 110 million, out of which about 64\% reside in the urban areas (GOP 2017). It has a high population density of about 536 persons per square kilometer, increasing susceptibility towards the spread of COVID-19. Out of the total COVID-19 confirmed patients, about 37\% were located in the province of Punjab (GOP 2021). Islamabad is the capital tertiary of Pakistan with more than two million inhabitants, but due to limited area, it has the highest average population density of 2,215 persons per square kilometers (GOP 2017). The city is the gateway to the country for foreign travelers and provides habitation to people from the whole country. Islamabad had 81,116 
confirmed patients of COVID-19 (GOP 2021). Accordingly, the main referral hospital of Islamabad was also selected for this study.

In Pakistan, limited studies have been conducted to get the epidemiological aspect, clinic pathological parameters, and comorbidities of COVID-19 patients. This study is aimed to expand our knowledge about the COVID-19 pandemic by assessing the symptomatic hospitalized COVID-19 patients based on the epidemiological, clinical, and laboratory characteristics. It is hoped that this study shall contribute to a better understanding of COVID-19 patient risk factors and the assessment of the severity and outcome of disease that would be valuable for preventive interventions, treatment strategies, and overall patient management. The comparative cross-sectional study was conducted in the leading hospitals designated for COVID-19 treatments, i.e., Mayo Hospital Lahore, Jinnah Hospital Lahore, Sheikh Zaid Hospital Lahore, University of Health Sciences, Lahore, Nishtar Hospital Multan, Victoria Hospital Bahawalpur, Pakistan Institute of Medical Sciences (PIMS) Islamabad and Infectious Treatment Centre (IHITC) Islamabad.

\section{Materials and Methods}

\subsection{Sampling Technique}

A non-probability convenience sampling technique was used for the selection of the study population. qPCR confirmed SARS-CoV-2 positive patients aged >18 years admitted in the isolation wards of the selected hospitals were selected after taking permission from the respective administration. These patients were divided into mild-tomoderate and severe categories using the operational definitions of "Chinese Clinical Guidance for COVID-19 Pneumonia Diagnosis and Treatment," published by the Chinese National Health Commission (Gao, Tian, and Yang 2020). The patients in the ward meeting the case definition for COVID-19 with and without evidence of viral pneumonia were categorized as mild-to-moderate. Whereas patients in intensive care units with clinical signs of pneumonia (fever, cough, dyspnea, tachypnea), including the following: respiratory rate $>30 \mathrm{breaths}^{\mathrm{min}}{ }^{-1}$; severe respiratory distress; or oxygen saturation $(\mathrm{SpO} 2)<90 \%$ on room air, were considered as severe. The estimated sample size was $\sim 450$ patients using the WHO formula and considering the anticipated population proportion (Yang et al. 2020).

\subsection{Data Collection/Measurements}

Before entering the isolation wards, guidelines and SOPs of each hospital were adopted. A detailed questionnaire was prepared with the assistance of three medical consultants for the collection of information, which was based on similar studies (Kirchberger et al. 2021; Al Mutair et al. 2020; Yegorov et al. 2021). It included demographic data (age, gender), family type (nuclear, extended), source of infection (travel history, contact with COVID-19 patient, etiology, clinical features (upper and lower respiratory tract \& GIT symptoms), Co-morbidities (diabetes mellitus, hypertension, chronic liver disease, chronic obstructive pulmonary disease, ischemic heart disease, cancer, tuberculosis, etc.), laboratory values (complete blood count, biochemical parameters, coagulation profile, inflammatory biomarkers for organ function and analysis of immunological responses), and treatment given (antibiotics oral/IV?, antiviral, steroids, I/V fluids, orogastric fluids, antimalarial and any experimental drug), length 
of hospitalization, and time taken to get the negative result of qPCR for SARS-CoV-2 ( $1^{\text {st }}$ qPCR negative Report). The digital images of the Chest CT scan of COVID-19 patients were obtained from selected hospitals and shared with experienced radiologists for characteristic disease findings.

\subsection{Statistical Analysis}

Data were entered, cleaned, and analyzed using Statistical Package for Social Sciences (SPSS)V.23. The quantitative variables like age and laboratory parameters were presented in mean and standard deviation. In contrast, qualitative data like clinical features, comorbidities, and demography were presented in frequency and percentages. The relationship between COVID-19 with clinic-pathological parameters and comorbidities among mild-tomoderate and severe patients was assessed using the Chi-square test $(p \leq 0.05)$. Means were compared using the student's $t$-test or ANOVA where applicable. Bar and pie diagrams were used to present categorical data where applicable.

\section{Results}

\subsection{Demography}

Four hundred and fifty-two (452) patients with confirmed COVID-19 diseases, admitted to five leading hospitals in different cities of the country, were included in this study. Among these, 279 (61.7\%) patients were male, and 173 $(38.2 \%)$ were female (Figure 1). The mean age of patients in this study was $(58+14.42)$ years old. Overall, patients aged $<50$ years were minor in number [126 (27.88\%) with a mean age of 40+7.83], compared to patients aged $\geq 50$ years [326 $(72.12 \%)$ with a mean age of $65+9.13$ years]. Mild-to-moderate (non-ICU) cases were higher in the age group $<50$ years old patients, i.e. [83 (34.73\%)], whereas the severe (ICU) cases numbered were $43(20.19 \%)$ in this age group. In a group with $>50$ years old patients, severe cases were seen more, i.e., 170 (79.81\%) compared to the 156 moderate cases (65.27\%). Most of the patients belonged to extended family type 294(65\%) compared to nuclear family $158(35 \%)$. However, the severity of the disease was insignificant between extended and nuclear family types $(p=0.429)$. Overall, 127(27.3\%) patients had a history of exposure to the infected environment; 54(11.9\%) patients were with travel history, while for $274(60.6 \%)$ patients, the cause of acquiring infection was unknown. The severity of the disease was insignificant between the source of COVID-19 infection $(p=0.496)$. Detailed demographic information is summarized in Table 1.

\subsection{Clinical Features of SARS-CoV-2 infected Patients}

The most common symptoms of illness in the COVID-19 patients were fever $(n=364 ; 80 \%)$, followed by dyspnea at rest $(\mathrm{n}=343 ; 75 \%)$ and cough $(\mathrm{n}=261 ; 57 \%)$. Small percentage of COVID-19 patients had fatigue ( $\mathrm{n}=138$; $30 \%)$, pneumonia $(\mathrm{n}=89 ; 19 \%)$, myalgias and generalized body aches $(\mathrm{n}=75 ; 16 \%)$. Vomiting $(\mathrm{n}=61 ; 13 \%)$, headache $(n=36: 7.9 \%)$,-sore throat $(n=33 ; 7.3 \%)$, diarrhea $(n=33 ; 7.3 \%)$, sputum production $(n=19 ; 4.2 \%)$, nausea $(\mathrm{n}=13 ; 2.9 \%)$, loss of taste $(\mathrm{n}=12 ; 2.7 \%)$, rhinorrhea $(\mathrm{n}=12 ; 2.7 \%)$, anosmia $(\mathrm{n}=7 ; 1.5 \%)$, nasal congestion $(\mathrm{n}=5$; $1.1 \%$ ) and abnormal Chest X-ray $\mathrm{n}=36(7.9 \%)$ were also observed. Some clinical manifestation differed significantly between mild-to-moderate and severe patients. Symptoms of dyspnea, pneumonia, respiratory distress and abnormal Chest X-ray findings were more pronounced in severe patients as compared to mild-to-moderate cases $(p<0.001)$. 
On the contrary symptoms of fatigue $(\mathrm{p}<0.001)$ and loss of taste $(\mathrm{p}=0.04)$ were seen in mild/moderate cases...? Tabulated summary of clinical feature of SARS-CoV-2 infected patients are shown in Table 2.

\subsection{COVID-19 patients with comorbidities}

Compared mild-to-moderate patients, severe patients had underlying co-morbidities such as hypertension ( $\mathrm{n}=104$; $48.8 \%)$, type 2 diabetes $(n=82 ; 38.5 \%)$, ischemic heart disease $(n=36 ; 16.9 \%)$. Other diseases included chronic kidney disease $(\mathrm{n}=10 ; 4.7 \%)$, asthma $(\mathrm{n}=6 ; 2.8 \%)$, immunocompromised state $(\mathrm{n}=6 ; 2.8 \%)$, COPD $(\mathrm{n}=7 ; 3 \%)$, liver disease $(n=2 ; 0.9 \%)$ and history of smoking $(n=3: 1.4 \%)$. The severe patient included a significantly high percentage of hypertension $(p=0.007)$ and COPD $(p=0.029)$. These co-morbidities impact outcome of disease severity and COVID-19 mortality. A comprehensive comparison is shown in Table 3.

\subsection{Laboratory parameters}

The mean values of Complete Blood Count (CBC) were significantly high in severe patients as compared to mild-tomoderate, in terms of WBC $[(14864.70 \pm 5821.73$-vs-11055.94 \pm 4344.73$), p<0.001)]$, platelets $[(249,672 \pm$ 104826.59 vs $246447.36 \pm 83141.91), p=0.004)]$ and neutrophil $[(9.99 \pm 4.93$ vs $8.19 \pm 3.27), p<0.001)]$. Similarly, the coagulation profile (D-dimer) was significantly high in mild-to-moderate patients $(2610.00 \pm 3607.04)$ as compared to severe patients [2213.67 $\pm 2823.36(\mathrm{mg} / \mathrm{L}), p<0.001)]$. Regarding liver function test, total Bilirubin was significantly high in severe patients $(0.91 \pm 1.41)$, while it was $(0.54 \pm 0.25)$ in mild-to-moderate patients (umol/liter; $p=0.054$ ). For renal function test, serum creatinine was significantly high in mild-to-moderate group $(1.22 \pm 0.64)$, while it was $(0.81 \pm 0.25$ mole/liter; $p=0.016)$ in severe patients. LDH was significantly high in mildto-moderate group $(619.00 \pm 257.32)$ than severe group $[(587.58 \pm 178.31), p<0.001)]$. Furthermore, severe patients had significantly high values of CRP and ferritin $(84.68 \pm 57.25)$ and $(996.81 \pm 892.21)(\mathrm{mcg} / \mathrm{liter} ; p<$ 0.001 ) respectively as compared to the mild-to-moderate group of SARS-CoV-2 infected patients. From illness to discharge, the average length of hospital stay was longer in severe patients $(10.79 \pm 7.00$ as compared to the mild-tomoderate patients $(5.89 \pm 3.41 ; p<0.001)$. Detailed comparison of laboratory parameters is presented in Table 4 .

\subsection{Medications used in the treatment}

The Table 5 summarized the medication given to the SARS-CoV-2 infected patients. Almost all SARS-CoV-2 infected patients, spanning from mild-to-moderate and severe had combination of antiviral, antibacterial, corticosteroid-based medication combined with oxygen therapy. Only two critically ill patients were on invasive ventilators, while others were managed with non-invasive ventilation. As compared mild-to-moderate patients, significantly percentage of severe patients were treated with Dexamethasone $[(\mathrm{n}=211 ; 99 \%$ vs $207 ; 86.6 \%, p<$ 0.001)], [Remdesivir ( $\mathrm{n}=178 ; 83.5 \%$ vs $136 ; 56.9 \%, p<0.001)]$, Meropenem [(n=121;56.8\% vs $\mathrm{n}=76 ; 31.8 \%, p<$ $0.001)]$, heparin $[(\mathrm{n}=112 ; 52.6 \%$ vs $\mathrm{n}=75 ; 31.4 \% ; p<0.001)]$ and Tocilizumab $[(\mathrm{n}=14 ; 6.6 \%$ vs $\mathrm{n}=1 ; 0.42 \% ; p<$ $0.001)]$.

\subsection{Correlation between Laboratory Parameters}

A significant correlation was assessed among laboratory parameters that are summarized in (Table 6):

i. A highly significant positive correlation was evaluated between ferritin and Hb, WBC, ALT/SGPT, total bilirubin, CRP, and LDH and had a highly negative correlation with lymphocytes. 
ii. D-dimer had a highly positive significant correlation with WBC, INR, procalcitonin, and LDH.

iii. Hb had a highly positive significant correlation with ALT/SGPT and hematocrit. In contrast, it was negatively correlated with CRP and sodium.

iv. $\quad$ WBC had a highly positive significant correlation with neutrophil, LDH, CRP, and INR.

v. A highly significant positive correlation was assessed between hematocrit and ALT/SGPT.

vi. INR had a highly positive significant correlation with neutrophils.

vii. CRP had a highly positive significant correlation with procalcitonin, neutrophil, and LDH, negatively correlated with potassium.

viii. LDH had a highly positive correlation with neutrophils.

ix. Platelets had a negative correlation with sodium and total bilirubin.

\subsection{Chest CT Scan Findings}

The patients that underwent Chest CT scans were also assessed in this study and summarized in Table 7 and Figure 2. The mean age of these patients was $(57 \pm 12.6)$ years, including $76.7 \%$ males and $23.3 \%$ females. The mean percentage of lung involvement in males was $(51.3 \pm 15.8)$, and it was $(54.3 \pm 14.3)$ in female patients. Only $20 \%$ of patients had the age $\leq 50$ years $(38.3 \pm 7.7)$, while a high number of patients $(80 \%)$ had the age of $>50$ years (62.4 \pm 8.1$)$. The most common findings were Ground Glass Opacity (GGO) ( $\mathrm{n}=28,93.3 \%)$, mixed pattern of consolidation $(\mathrm{n}=12,40 \%)$, and interlobular septal thickening $(\mathrm{n}=6,20 \%)$. Small percentage of patients had GGO and Opacities $n=2(6.7 \%)$, infiltration $(n=2,6.7 \%)$, consolidation $(n=1,3.3 \%)$ and-cavitation $(n=1,3.3 \%)$. Seventeen (57.7\%) had five affected lobes, 8 (26.7\%) had four affected lobes, $2(6.7 \%)$ had three affected lobes, $2(6.7 \%)$ had two affected lobes, and $1(3.3 \%)$ had one affected lobe Figure 2.

\section{Discussion}

\subsection{Demography}

The number of male patients was high compared to female patients, presumably due to men's increased vulnerability to COVID 19 due to various reasons. It has been attributed that females showed more resistance to COVID-19 infection than men due to differences in sex hormones and lower expression of receptors (ACE-2) (Bwire 2020). Others have reported that men show high mortality from heart disease and diabetes, contributing to sex-based severity from COVID-19 (Pradhan and Olsson 2020; Tian et al. 2020). The older aged peoples are at high risk to catch the SARS-CoV-2 due to weak immune system and high prevalence of comorbidities, and this susceptibility has also been concluded in different studies (Amber L. Mueller, Maeve S.McNamara, and David A. Sinclair 2020; Al Mutair et al. 2020; Yegorov et al. 2021). The high number of COVID-19 patients in the study belonged to the extended family type, presumably due to crowded living conditions that favored the spread of disease. The same has been concluded in different studies (Noreen et al. 2020; Ramadhana 2020).

The source of infection was unknown for $60 \%$ of COVID-19. It has been reported in other studies that the prevalence of asymptomatic carriers is difficult to determine, requires comprehensive screening. This would provide 
It is made available under a CC-BY-NC-ND 4.0 International license .

essential information on hidden viral strains circulating in the community, and the rate of such carriers would be different in high-density urban areas (Ahmed, Colebunders, and Siewe Fodjo 2020; Cloutier et al. 2020). Similarly, it has also been reviewed that the majority of asymptomatic patients appear to have a milder clinical course during hospitalization, but the severity of the symptoms in asymptomatic patients among all confirmed cases varies widely (from $1.95 \%$ to $87.9 \%$ ), according to the study setting and the populations studied (Han et al. 2020). It was concluded that patients with travel history from abroad (11\%) were positive for COVID-19 on the health authorities' investigation. Since Pakistan has a high frequency of travel and trade with China and Iran, it has been reported that the risk of viral transmission across borders increases (Javed et al. 2021; Noreen et al. 2020).

Furthermore, an inclination to withhold travel history to high-risk epidemic regions also results in unpredictable outcomes (Wei et al. 2020). The susceptibility of getting infected while coming in contact with confirmed COVID19 patients (27\%) may be attributed to person-to-person transmission, as reported in several similar studies (Cloutier et al. 2020; Lechien et al. 2020; Martinez-Fierro et al. 2021). It was concluded that the average number of days spent in the hospital was significantly high in severe patients compared to mild/moderate patients $(10$ vs. 5 days, $p<$ $0.001)$.

\subsection{Clinical Features}

Symptoms of illness such as fever (80\%), shortness of breath (75\%), and cough (57\%) are most common, predominantly due to the reason that the disease is reported to affect the lower respiratory system. Presumably, due to similar reasons, the symptoms of shortness of breath, pneumonia, and abnormal chest X-ray were significantly high in severe patients. The results coincide with other studies wherein it has been reported that fever, cough, fatigue, and shortness of breath are common symptoms in severe COVID-19 patients (Durrani et al. 2020; Al Mutair et al. 2020). The association of the lower respiratory system in affecting the severity of COVID-19 patients has also been reported in different studies (Brosnahan et al. 2020; Hannawi et al. 2021; Marinari, Danny, and Miller 2019).

Other symptoms of COVID-19 patients, including myalgia and generalized body aches, vomiting, headaches, etc., were presumably associated symptoms of fever, cough, and shortness of breath. Similar findings were reported in various studies from different regions (P. Sun et al. 2020; Weng, Su, and Wang 2021, 2021). An alternative diagnosis should also be considered to prevent weak opinion, mainly other infectious diseases like pneumonia of bacterial etiology, bacteremia, and respiratory infections such as exacerbation of COPD, cardiovascular disorders like acute heart failure. Systematic evaluation of heart function should be done in COVID-19 suspected patients. Ruling out other differentials with similar clinical features prevents extended hospital stay in isolation wards, shortage of beds required for critical COVID-19 patients, thereby reducing the burden on the healthcare system.

\subsection{Comorbidities}

The predominance of patients had a longstanding history of hypertension (48.8\% vs. 35.9\%), type 2 diabetes (38.5\% vs. $31.4 \%$ ), ischemic heart disease (16.9\% vs. 12.5\%). In severe COVID-19 patients, these may be linked to multiple factors, among them the significant ones the aged patients, reduced systemic oxygenation intake due to pneumonia, concomitantly increased cardiac demand, and use of ACE inhibitors. The high percentage of hypertension and chronic obstructive pulmonary disease (COPD) in the severe patient may also be linked to similar reasons along with underlying poor lung reserves or increased expression of ACE-2 receptors in small airways. Many studies 
found a high risk of infection in cardiovascular, pulmonary, and renal patients (De Almeida-Pititto et al. 2020; Leung et al. 2020). Most importantly, studies revealed that high mortality ratios in COVD-19 patients were associated with cardiovascular and renal complications of diabetes and independently with glycemic control and BMI (Dyusupova et al. 2021; Holman et al. 2020; Richardson et al. 2020).

\subsection{Laboratory Parameters}

Complete blood count, coagulation profile, biochemical parameters, and inflammatory mediators predict disease severity and outcomes. Values of WBC, platelets, neutrophil, total Bilirubin, CRP, and ferritin were significantly high in severe patients compared to mild/moderate. The study signifies the usefulness of biomarkers in assessing the severity of COVID-19 infection in patients, which may help to improve the treatment of disease. The results of this study are in line with contrasting findings in similar studies. The increase of CRP and ferritin in critically ill COVID-19 patients has been measured in various findings (Hannawi et al. 2021; Al Mutair et al. 2020; Wang et al. 2020). The same tendency was observed for WBC, platelets, neutrophils, and bilirubin (Taj et al. 2021; Yegorov et al. 2021; Yin et al. 2020). A significantly positive correlation was observed between the ferritin and laboratory parameters, including $\mathrm{Hb}, \mathrm{WBC}, \mathrm{ALT} / \mathrm{SGP}$, total bilirubin, CRP, LDH, while negatively correlated with lymphocytes. Low D-dimer, serum creatinine, and LDH were observed in severe patients compared to mild-tomoderate patients. This may be because regular administration of anticoagulant drugs for treatment in severe patients decreased the levels of D-dimers in patients presumably. Similar results were obtained in studies conducted to assess on-protocol COVID-19 patients (Kamel et al., 2021; Tassiopoulos et al. 2021). Apparently, due to similar reasons, the D-dimer had a highly positive significant correlation with WBC, INR, procalcitonin, and LDH. A retrospective study by (Taj et al. 2021) on confirmed covid -19 patients concluded that leukocytosis, neutrophilia, elevated neutrophil to lymphocyte ratio, activated partial thromboplastin time (APTT), D-dimer, lactate dehydrogenase (LDH), and serum ferritin and C-Reactive Protein (CRP) are associated with severity of the disease.

\subsection{Medications used in the treatment}

A significantly high percentage of severe patients were treated with steroid (Dexamethasone), antiviral (Remdesivir), antibiotic (Meropenem), anticoagulant (Heparin), and immunosuppressive (Tocilizumab) as compared to mild/moderate patients. Dexamethasone helps control inflammation of the lower respiratory tract and its immunosuppressive role (Selvaraj et al. 2020). Similarly, the use of Remdesivir had provided evidence of lowering respiratory tract infection (Beigel et al. 2020). Antibiotics are reported to have safely and effectively treated most bacterial cases of pneumonia. Antibiotics have played an effective role in treating superimposed bacterial infections, such as bacterial cases of pneumonia in COVID-19 patient settings (Beovic et al. 2020; Ginsburg and Klugman 2020). Activation of the coagulation cascade leading to severe hypercoagulability has been detected in COVID-19 patients. Therefore, it has been recommended that early anticoagulation may reduce coagulopathy, microthrombus formation, and the risk of organ damages (Becker 2020; Gozzo et al. 2020; Richardson et al. 2020). It has been reported that treatment with Tocilizumab, whether administered intravenously or subcutaneously, might reduce the risk of invasive mechanical ventilation or death in patients with severe COVID-19 pneumonia (Guaraldi et al. 2020). 


\subsection{Radiological findings:}

\section{a. Chest Xray:}

Chest X-ray is a valuable tool in assessing disease progression and severity. In COVID-19 patients, it may be normal initially but later may follow a characteristic pattern of progression from bilateral lower predominant zone to upper zones, vertically extend peripheral to diffuse in critical ICU patients showing a picture of ARDS. It has been concluded that in the initial Chest X-ray on admission, involvement of $>4$ zones have been linked to increased severity and unfavorable outcome.

\section{b. Chest CT Scan:}

Non-enhanced Chest CT is a vital component in the diagnosis of patients suspected of COVID-19 infection. The pattern of GGO, GGO, and consolidation, and interlobular septal thickening were the most prominent findings among infected patients of different age groups, gender, and severity. The pattern of findings is somewhat similar to that described in related studies on severe acute respiratory syndrome (A. et al. 2020; Pan et al. 2020; Wu et al. 2020). In critical patients, honey-combing pattern, traction bronchiectasis, interlobar pleural traction can be appreciated. Follow-up CT after six months may show fibrotic changes in such patients. Combination RT-PCR analysis and Chest CT scan increase the sensitivity and specificity of Covid-19 diagnosis to $88 \%$ and 100\%, respectively. Semi-quantitative CT Severity Score System (CT-SSS) helps in showing the extent of pulmonary involvement. It is as follow,

0 score $=$ no involvement

1 score $=<5 \%$ involvement

2 score $=5-25 \%$ involvement

3 score $=26-49 \%$ involvement

4 score $=50-75 \%$ involvement

5 score $=>75 \%$ involvement

Total CT severity score is calculated by summing up the individual lobe score, with a cumulative score ranging from (0-25). CT score $>18$ has been correlated with increased severity, mortality, and worse prognosis. In another study, it has been reported that a CT score $>7$ has been linked to increased chances of developing the post-covid syndrome.

\section{Conclusion}

Older patients, predominantly male was more in number in both groups with comorbidities, mainly hypertension, type 2 diabetes, and ischemic heart. Preventive measures against COVID-19 must be followed, and surveillance for asymptomatic carriers should be increased. Excessive use of antibacterial, antiviral, anticoagulants, and drugs for 
pain management were noticed. Early detection based on laboratory-based biomarkers may prevent the severity of illness.

Acknowledgment: This study is part of the Rapid COVID Project (RRG\# 211) funded by the Higher Education Commission (HEC) and the World Bank. The authors duly acknowledged the hospital administrations' support, patients, and their families who participated in this study.

ETHICS Statement: This project was conducted under approval number UHS/REG-20/ERC/1758 from the University of Health Sciences Lahore Ethical Review Committee. Written informed consents were provided by the patients/participants to participate in this study.

Author Contributions and Competing Interest: All authors contributed to the planning, interviewing the participants, data collection, data analysis, draft writeup, improvement, and approved the final version of the manuscript. None of the authors declared a competing interest.

\section{Reference:}

A., Bernheim et al. 2020. "Chest CT Findings in Coronavirus Disease-19 (COVID-19): Relationship to Duration of Infection.” Radiology 295(3): 200463.

Ahmed, Mohammed A.M., Robert Colebunders, and Joseph Nelson Siewe Fodjo. 2020. "Evidence for Significant COVID-19 Community Transmission in Somalia Using a Clinical Case Definition." International Journal of Infectious Diseases 98: 206-7.

De Almeida-Pititto, Bianca et al. 2020. "Severity and Mortality of COVID 19 in Patients with Diabetes, Hypertension and Cardiovascular Disease: A Meta-Analysis." Diabetology and Metabolic Syndrome 12(1): $1-12$.

Amber L. Mueller, Maeve S.McNamara, and David A. Sinclair. 2020. "Why Does COVID-19 Disproportionately Affect Older People?" Aging 12(10): 9959-81.

Becker, Richard C. 2020. "COVID-19 Update: Covid-19-Associated Coagulopathy." Journal of Thrombosis and Thrombolysis 50(1): 54-67.

Beigel, John H. et al. 2020. "Remdesivir for the Treatment of Covid-19 — Final Report." New England Journal of Medicine 383(19): 1813-26.

Beovic, Bojana et al. 2020. "Antibiotic Use in Patients with COVID-19: A 'snapshot' Infectious Diseases International Research Initiative (ID-IRI) Survey.” Journal of Antimicrobial Chemotherapy 75(11): 338690.

Brosnahan, Shari B. et al. 2020. "Covid-19 and Respiratory System Disorders Current Knowledge, Future Clinical and Translational Research Questions.” Arteriosclerosis, Thrombosis, and Vascular Biology (November): 2586-97.

Bwire, George M. 2020. “Coronavirus: Why Men Are More Vulnerable to Covid-19 Than Women?” SN Comprehensive Clinical Medicine 2(7): 874-76.

Cloutier, Lyne et al. 2020. "Asymptomatic Carriers of COVID-19 in a Confined Adult Community Population in Quebec: A Cross-Sectional Study.” American Journal of Infection Control 49: 2020-22. 
Durrani, Misbah, Inam Ul Haq, Ume Kalsoom, and Anum Yousaf. 2020. "Chest X-Rays Findings in Covid 19 Patients at a University Teaching Hospital-a Descriptive Study." Pakistan Journal of Medical Sciences 36(COVID19-S4): S22-26.

Dyusupova, Azhar et al. 2021. "Clinical Characteristics and Risk Factors for Disease Severity and Mortality of COVID-19 Patients with Diabetes Mellitus in Kazakhstan: A Nationwide Study." Heliyon 7(3): e06561.

Gao, Jianjun, Zhenxue Tian, and Xu Yang. 2020. "Breakthrough: Chloroquine Phosphate Has Shown Apparent Efficacy in Treatment of COVID-19 Associated Pneumonia in Clinical Studies." Bioscience Trends 14(1): 72-73.

Ginsburg, Amy Sarah, and Keith P. Klugman. 2020. "COVID-19 Pneumonia and the Appropriate Use of Antibiotics." The Lancet Global Health 8(12): e1453-54.

GOP. 2017. Punjab Development Statistics 2017.

. 2021. "Pakistan Cases Details.” https://covid.gov.pk/stats/pakistan (May 30, 2021).

Gozzo, Lucia et al. 2020. "The Potential Role of Heparin in Patients With COVID-19: Beyond the Anticoagulant Effect. A Review." Frontiers in Pharmacology 11(August): 1-8.

Grant, Michael C. et al. 2020. "The Prevalence of Symptoms in 24,410 Adults Infected by the Novel Coronavirus (SARS-CoV-2; COVID-19): A Systematic Review and Meta-Analysis of 148 Studies from 9 Countries." PLOS ONE 15(6 June).

Gu, Jiang, and Christine Korteweg. 2007. "Pathology and Pathogenesis of Severe Acute Respiratory Syndrome." The American Journal of Pathology 170(4): 1136-47.

Guaraldi, Giovanni et al. 2020. "Tocilizumab in Patients with Severe COVID-19: A Retrospective Cohort Study." The Lancet Rheumatology 2(8): e474-84.

Han, Dongsheng et al. 2020. "Covid-19: Insight into the Asymptomatic Sars-Cov-2 Infection and Transmission." International Journal of Biological Sciences 16(15): 2803-11.

Hannawi, Suad et al. 2021. "Clinical and Laboratory Profile of Hospitalized Symptomatic COVID-19 Patients: Case Series Study From the First COVID-19 Center in the UAE." Frontiers in Cellular and Infection Microbiology 11(February): 1-10.

Holman, Naomi et al. 2020. "Risk Factors for COVID-19-Related Mortality in People with Type 1 and Type 2 Diabetes in England: A Population-Based Cohort Study." The Lancet Diabetes and Endocrinology 8(10): 823-33.

Javed, Aneela et al. 2021. "Coding-Complete Genome Sequence of a SARS-CoV-2 Strain Isolated in Gilgit, Pakistan" ed. Simon Roux. Microbiology Resource Announcements 10(13). https://journals.asm.org/doi/10.1128/MRA.01151-20 (September 22, 2021).

Kamel, Fatemah O. et al. 2021. "Clinical and Hematologic Presentations of Adults with COVID-19 Patients in Jeddah: A Case Control Study.” Journal of Infection and Public Health.

Khalid, Atiqa, and Sana Ali. 2020. "COVID-19 and Its Challenges for the Healthcare System in Pakistan." Asian Bioethics Review 12(4): 551-64.

Kirchberger, Inge et al. 2021. "COVID-19 Risk Perceptions, Worries and Preventive Behaviors in Patients with Previous Pulmonary Embolism.” Thrombosis Research 202(March): 77-83. 
Lechien, Jerome R. et al. 2020. "Clinical and Epidemiological Characteristics of 1420 European Patients with Mildto-Moderate Coronavirus Disease 2019.” Journal of Internal Medicine 288(3): 335-44.

Leung, Janice M., Masahiro Niikura, Cheng Wei Tony Yang, and Don D. Sin. 2020. "COVID-19 and COPD.” European Respiratory Journal 56(2): 1-9.

Lu, Hongzhou, Charles W. Stratton, and Yi $\square$ Wei Tang. 2020. "Outbreak of Pneumonia of Unknown Etiology in Wuhan, China: The Mystery and the Miracle." Journal of Medical Virology 92(4): 401-2.

Lvov, D. K., and S. V. Alkhovsky. 2020. "[Source of the COVID-19 pandemic: ecology and genetics of coronaviruses (Betacoronavirus: Coronaviridae) SARS-CoV, SARS-CoV-2 (subgenus Sarbecovirus), and MERS-CoV (subgenus Merbecovirus).].” Voprosy Virusologii 65(2): 62-70.

Marinari, Lawrence A, Madeline A Danny, and Wallace T Miller. 2019. "Sporadic Coronavirus Lower Respiratory Tract Infection in Adults: Chest CT Imaging Features and Comparison with Other Viruses." European Respiratory Journal 54(suppl 63): PA4547.

Martinez-Fierro, Margarita L. et al. 2021. "The Role of Close Contacts of COVID-19 Patients in the SARS-CoV-2 Transmission: An Emphasis on the Percentage of Nonevaluated Positivity in Mexico." American Journal of Infection Control 49(1): 15-20.

Mueller, Amber L., Maeve S. McNamara, and David A. Sinclair. 2020. "Why Does COVID-19 Disproportionately Affect Older People?" Aging 12(10): 9959-81.

Mushtaq, Atifa et al. 2020. "Evaluation of the COVID-19 Laboratory-Based Surveillance System in IslamabadPakistan 2020." Global Biosecurity 1(4). https://jglobalbiosecurity.com/article/10.31646/gbio.73/ (September 12, 2021).

Al Mutair, Abbas et al. 2020. "Clinical, Epidemiological, and Laboratory Characteristics of Mild-to-Moderate COVID-19 Patients in Saudi Arabia: An Observational Cohort Study.” European Journal of Medical Research 25(1): 1-8.

Nawaz, Ahsan et al. 2020. "Epidemic Spread and Its Management Through Governance and Leadership Response Influencing the Arising Challenges Around COVID-19 in Pakistan-A Lesson Learnt for Low Income Countries With Limited Resource." Frontiers in Public Health 8: 573431.

NCOC. 2021a. "COVID and Vaccine Statistics of Pakistan." National Command and Operation Center. https://ncoc.gov.pk/\#section2.

2021b. "National Command and Operation Center, Goverment of Islamic Republic Pakistan." National Command and Operation Center. https://ncoc.gov.pk/.

—. 2021c. "Standard Operating Procedures (SOPs)/Guidelines." National Command and Operation Center. https://ncoc.gov.pk/sop.php.

Noreen, Nadia et al. 2020. "Coronavirus Disease (COVID-19) Pandemic and Pakistan; Limitations and Gaps." Limitations and Gaps. Global Biosecurity 1(3).

Oberemok, Volodymyr V. et al. 2020. "SARS-CoV-2 Will Continue to Circulate in the Human Population: An Opinion from the Point of View of the Virus-Host Relationship." Inflammation Research 69(7): 635-40.

Pan, Yueying et al. 2020. "Initial CT Findings and Temporal Changes in Patients with the Novel Coronavirus Pneumonia (2019-NCoV): A Study of 63 Patients in Wuhan, China." European Radiology 30(6): 3306-9. 
Pradhan, Ajay, and Per Erik Olsson. 2020. "Sex Differences in Severity and Mortality from COVID-19: Are Males More Vulnerable?” Biology of Sex Differences 11(1): 1-11.

Ramadhana, Maulana Rezi. 2020. “A Dataset for Emotional Reactions and Family Resilience during COVID-19 Isolation Period among Indonesian Families.” Data in Brief 31: 105946.

Richardson, Safiya et al. 2020. "Presenting Characteristics, Comorbidities, and Outcomes among 5700 Patients Hospitalized with COVID-19 in the New York City Area." JAMA - Journal of the American Medical Association 323(20): 2052-59.

Selvaraj, Vijairam, Kwame Dapaah-Afriyie, Arkadiy Finn, and Timothy P Flanigan. 2020. "Short-Term Dexamethasone in Sars-CoV-2 Patients." Rhode Island medical journal (2013) 103(6): 39-43.

Sun, Jiumeng et al. 2020. "COVID-19: Epidemiology, Evolution, and Cross-Disciplinary Perspectives.” Trends in Molecular Medicine 26(5): 483-95.

Sun, Pengfei et al. 2020. "Clinical Characteristics of Hospitalized Patients with SARS-CoV-2 Infection: A Single Arm Meta-Analysis.” Journal of Medical Virology 92(6): 612-17.

Taj, Sadia et al. 2021. "Role of Hematological Parameters in the Stratification of COVID-19 Disease Severity." Annals of medicine and surgery (2012).

Tassiopoulos, Apostolos K. et al. 2021. "D-Dimer-Driven Anticoagulation Reduces Mortality in Intubated COVID19 Patients: A Cohort Study With a Propensity-Matched Analysis." Frontiers in Medicine 8(February): 110.

Tian, Jianbo et al. 2020. "Clinical Characteristics and Risk Factors Associated with COVID-19 Disease Severity in Patients with Cancer in Wuhan, China: A Multicentre, Retrospective, Cohort Study." The Lancet Oncology 21(7): 893-903.

Wang, Guyi et al. 2020. "C-Reactive Protein Level May Predict the Risk of COVID-19 Aggravation." Open Forum Infectious Diseases 7(5): 1-5.

Wei, Lifeng et al. 2020. "Willingness and Beliefs Associated with Reporting Travel History to High-Risk Coronavirus Disease 2019 Epidemic Regions among the Chinese Public: A Cross-Sectional Study." BMC Public Health 20(1): 1-9.

Weng, Lin Man, Xuan Su, and Xue Qiang Wang. 2021. "Pain Symptoms in Patients with Coronavirus Disease (COVID-19): A Literature Review." Journal of Pain Research 14: 147-59.

WHO. 2020. "Naming the Coronavirus Disease (COVID-19) and the Virus That Causes It." World Health Organization. https://www.who.int/emergencies/diseases/novel-coronavirus-2019/technicalguidance/naming-the-coronavirus-disease-(covid-2019)-and-the-virus-that-causes-it.

—. 2021. "WHO Coronavirus (COVID-19) Dashboard." World Health Organization. https://covid19.who.int/.

Wu, Jiong et al. 2020. "Chest CT Findings in Patients with Coronavirus Disease 2019 and Its Relationship with Clinical Features." Investigative Radiology 55(5): 257-61.

Yang, Luhuan et al. 2020. "Epidemiological and Clinical Features of 200 Hospitalized Patients with Corona Virus Disease 2019 Outside Wuhan, China: A Descriptive Study.” Journal of Clinical Virology 129.

Yegorov, Sergey et al. 2021. "Epidemiology, Clinical Characteristics, and Virologic Features of COVID-19 Patients in Kazakhstan: A Nation-Wide Retrospective Cohort Study.” The Lancet Regional Health - Europe 4: 100096. 
medRxiv preprint doi: https://doi.org/10.1101/2021.09.25.21264111; this version posted September 27, 2021. The copyright holder for this preprint (which was not certified by peer review) is the author/funder, who has granted medRxiv a license to display the preprint in perpetuity.

It is made available under a CC-BY-NC-ND 4.0 International license .

Yin, Shiyu, Ming Huang, Dengju Li, and Ning Tang. 2020. "Difference of Coagulation Features between Severe Pneumonia Induced by SARS-CoV2 and Non-SARS-CoV2." Journal of Thrombosis and Thrombolysis: 36.

Zhou, Peng et al. 2020. "A Pneumonia Outbreak Associated with a New Coronavirus of Probable Bat Origin.” Nature 579(7798): 270-73. 


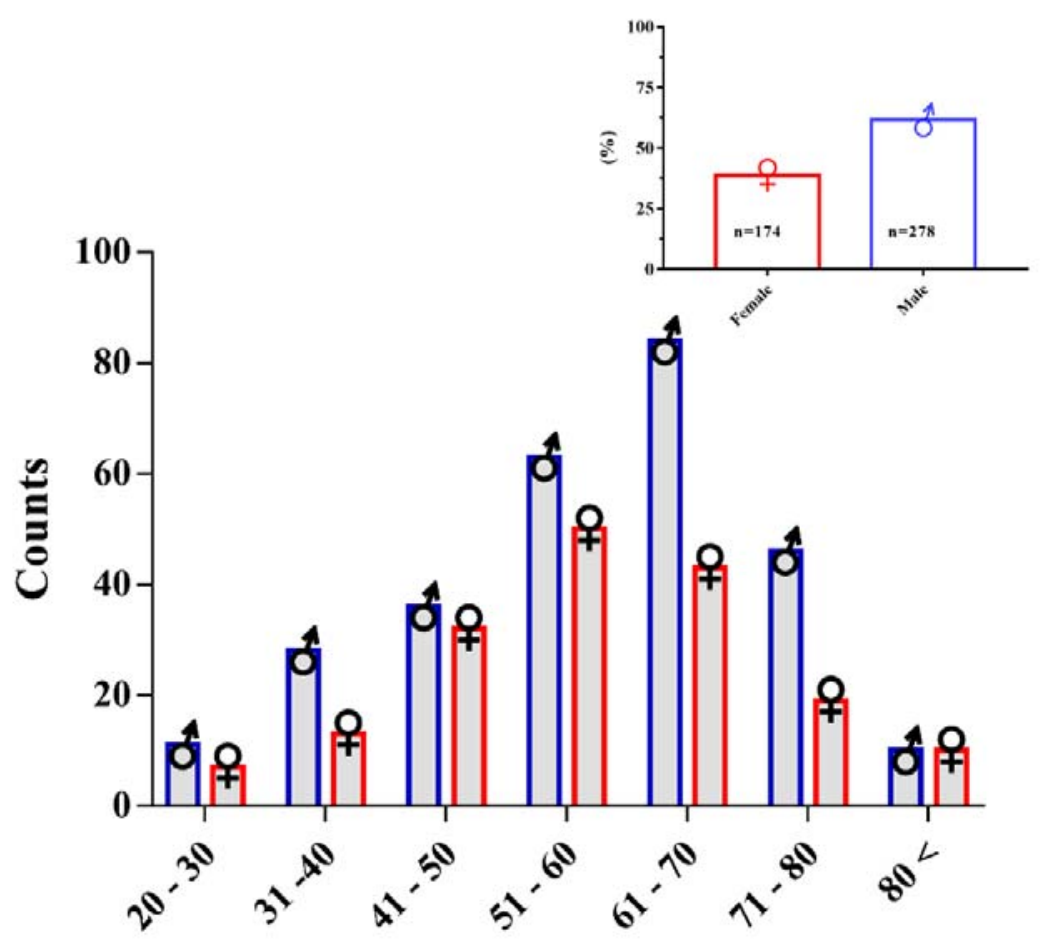

Figure 1: Gender wise distribution of the SARS-CoV-2 infected patients with age groups studied in this study. 
medRxiv preprint doi: https://doi.org/10.1101/2021.09.25.21264111; this version posted September 27, 2021. The copyright holder for this preprint (which was not certified by peer review) is the author/funder, who has granted medRxiv a license to display the preprint in perpetuity.

It is made available under a CC-BY-NC-ND 4.0 International license .

Table 1: Epidemiological Data of 452 symptomatic COVID-19 Patients

\begin{tabular}{|c|c|c|c|c|}
\hline Variables & Total $(n=452)$ & $\begin{array}{l}\text { Mild/Moderate } \\
(\mathrm{n}=\mathbf{2 3 9})\end{array}$ & Severe $(n=213)$ & $p$ value \\
\hline Age (years) & $58.52(14.42)$ & $55.75(15.1)$ & $61.62(13.0)$ & \multirow{5}{*}{ N/A } \\
\hline & 126(27.88), & 83(34.73), & 43(20.19) & \\
\hline $\operatorname{Mean}(\mathrm{SD})$ & $40.22(7.83)$ & $38.90(8.18)$ & $42.77(6.57)$ & \\
\hline$>50$ years $\mathrm{n}(\%)$ & $326(72.12)$, & 156(65.27), & 170(79.81\%), & \\
\hline $\operatorname{Mean}(\mathrm{SD})$ & $65.59(9.13)$ & $64.71(8.81)$ & $66.39(9.34 \%)$ & \\
\hline \multicolumn{5}{|l|}{ Gender } \\
\hline Male & $279(61.7 \%)$ & $137(49.2 \%)$ & $142(50.8 \%)$ & \multirow[b]{2}{*}{ N/A } \\
\hline Female & $173(38.2 \%)$ & $102(58.9 \%)$ & $71(41.1 \%)$ & \\
\hline \multicolumn{5}{|l|}{ Family Type } \\
\hline Nuclear & $158(35 \%)$ & $88(55.7 \%)$ & $70(44.3 \%)$ & \multirow{2}{*}{0.429} \\
\hline Extended & $294(65 \%)$ & $151(51.4 \%)$ & $143(48.6 \%)$ & \\
\hline \multicolumn{5}{|c|}{ Source of COVID-19 Infection } \\
\hline Travel History & $55(12.2 \%)$ & $33(60 \%)$ & $22(40 \%)$ & \multirow{3}{*}{0.496} \\
\hline Contact History & $124(27.4 \%)$ & $66(53.2 \%)$ & $58(46.8 \%)$ & \\
\hline $\begin{array}{l}\text { No known source for } \\
\text { COVID-19 }\end{array}$ & $273(60.4 \%)$ & $140(51.3 \%)$ & $133(48.7 \%)$ & \\
\hline
\end{tabular}

Data are $\mathrm{n}(\%)$ or mean(S.D.) unless otherwise indicated

$P$ values suggest the disparity between age groups, family type, and source of infection among mild/moderate and severe COVID-19 patients. The significance level for $p$ value $\leq$ is 0.05 . 
medRxiv preprint doi: https://doi.org/10.1101/2021.09.25.21264111; this version posted September 27, 2021. The copyright holder for this preprint (which was not certified by peer review) is the author/funder, who has granted medRxiv a license to display the preprint in perpetuity.

It is made available under a CC-BY-NC-ND 4.0 International license .

Table 2 Clinical Features of 452 symptomatic COVID-19 Patients

\begin{tabular}{|l|l|l|l|l|}
\hline Clinical Features & Total $(\mathbf{n}=\mathbf{4 5 2})$ & $\begin{array}{l}\text { Mild/Moderate } \\
(\mathbf{n = 2 3 9})\end{array}$ & Severe (n=213) & $\boldsymbol{p}$ value \\
\hline Fever or Chills & $364(80.5)$ & $187(78.2)$ & $177(83.1)$ & 0.234 \\
\hline Shortness / Difficulty of Breathing & $343(75.9)$ & $162(67.8)$ & $181(84.9)$ & $\mathbf{0 . 0 0 0}$ \\
\hline Cough & $261(57.7)$ & $134(56.1)$ & $127(59.6)$ & 0.448 \\
\hline Fatigue & $138(30.5)$ & $93(38.9)$ & $45(21.1)$ & $\mathbf{0 . 0 0 0}$ \\
\hline Pneumonia & $89(19.6)$ & $16(6.7)$ & $73(34.3)$ & $\mathbf{0 . 0 0 0}$ \\
\hline Muscle or body aches & $75(16.6)$ & $35(14.6)$ & $40(18.8)$ & 0.256 \\
\hline Vomiting & $61(13.5)$ & $34(14.2)$ & $27(12.7)$ & 0.680 \\
\hline Headache & $36(7.9)$ & $19(7.9)$ & $17(7.9)$ & 1.000 \\
\hline Abnormal chest X-Ray & $36(7.9)$ & $5(2.1)$ & $31(14.6)$ & $\mathbf{0 . 0 0 0}$ \\
\hline Sore throat & $33(7.3)$ & $14(5.9)$ & $19(8.9)$ & 0.277 \\
\hline Diarrhea & $33(7.3)$ & $15(6.3)$ & $18(8.5)$ & 0.469 \\
\hline Sputum production & $19(4.2)$ & $13(5.4)$ & $6(2.8)$ & 0.240 \\
\hline Nausea & $13(2.9)$ & $7(2.9)$ & $6(2.8)$ & 1.000 \\
\hline Loss of taste & $12(2.7)$ & $10(4.2)$ & $2(0.9)$ & $\mathbf{0 . 0 4 0}$ \\
\hline Runny Nose & $12(2.7)$ & $9(3.8)$ & $3(1.4)$ & 0.149 \\
\hline Loss of smell & $7(1.5)$ & $5(2.1)$ & $2(0.9)$ & 0.455 \\
\hline Congestion & $5(1.1)$ & $2(0.8)$ & $3(1.4)$ & 0.670 \\
\hline Data are no & & & \\
\hline
\end{tabular}

Data are $\mathrm{n}(\%)$.

$P$ values suggest the disparity between mild/moderate and severe COVID-19 patients—significance level for $p$-value $\leq 0.050$. 
medRxiv preprint doi: https://doi.org/10.1101/2021.09.25.21264111; this version posted September 27, 2021. The copyright holder for this preprint (which was not certified by peer review) is the author/funder, who has granted medRxiv a license to display the preprint in perpetuity.

It is made available under a CC-BY-NC-ND 4.0 International license .

Table 3 Comorbidities of 452 symptomatic COVID-19 Patients

\begin{tabular}{|l|l|l|l|l|}
\hline Co-Morbidities & $\begin{array}{l}\text { Total } \\
(\mathbf{n = 4 5 2})\end{array}$ & $\begin{array}{l}\text { Mild/Moderate } \\
(\mathbf{n = 2 3 9})\end{array}$ & Severe (n=213) & P value \\
\hline Hypertension & $190(42.0)$ & $86(35.9)$ & $104(48.8)$ & $\mathbf{0 . 0 0 7}$ \\
\hline Type 2 Diabetes Mellitus & $157(34.7)$ & $75(31.4)$ & $82(38.5)$ & 0.115 \\
\hline Ischemic Heart Disease & $66(14.6)$ & $30(12.5)$ & $36(16.9)$ & 0.230 \\
\hline Chronic Kidney Disease & $19(4.2)$ & $9(3.7)$ & $10(4.7)$ & 0.646 \\
\hline Asthma & $11(2.4)$ & $5(2.1)$ & $6(2.8)$ & 0.763 \\
\hline Immunocompromised state & $10(2.21)$ & $4(1.6)$ & $6(2.8)$ & 0.527 \\
\hline $\begin{array}{l}\text { Chronic Obstructive } \\
\text { Pulmonary Disease }\end{array}$ & $8(1.8)$ & $1(0.4)$ & $7(3.3)$ & $\mathbf{0 . 0 2 9}$ \\
\hline Smoking & & & & 0.670 \\
\hline Liver disease & $5(1.1)$ & $2(0.8)$ & $3(1.4)$ & 0.604 \\
\hline
\end{tabular}

Data are n (\%)

$P$ values suggest the disparity between mild/moderate and severe COVID-19 patients. Significance level for $p$ value $\leq 0.050$. 
medRxiv preprint doi: https://doi.org/10.1101/2021.09.25.21264111; this version posted September 27, 2021. The copyright holder for this preprint (which was not certified by peer review) is the author/funder, who has granted medRxiv a license to display the preprint in perpetuity.

It is made available under a CC-BY-NC-ND 4.0 International license .

Table 4 Laboratory Features of 452 symptomatic COVID-19 Patients

\begin{tabular}{|c|c|c|c|}
\hline Laboratory Parameters & Mild/Moderate & Severe & $p$ value \\
\hline \multicolumn{4}{|l|}{ Complete Blood Count } \\
\hline $\mathrm{Hb} \mathrm{g} / \mathrm{dl}$ & $12.64(2.15)$ & $12.67(2.27)$ & 0.966 \\
\hline WBC/cubic mm & $11055.94(4344.73)$ & $14864.70(5821.73)$ & 0.000 \\
\hline Haematocrit \% & $36.19(6.87)$ & $38.46(6.67)$ & 0.431 \\
\hline Platelets/cmm & $246447.36(83141.91)$ & 249672.91(104826.59) & 0.004 \\
\hline Neutrophils & $8.19(3.27)$ & 9.99(4.93) & 0.000 \\
\hline Lymphocytes & $1.47(0.83)$ & $1.47(1.18)$ & 0.458 \\
\hline Monocytes & $0.40(0.35)$ & $0.48(0.64)$ & 0.459 \\
\hline \multicolumn{4}{|l|}{ Coagulation Profile } \\
\hline D-Dimer & $2610.00(3607.04)$ & $2213.67(2823.36)$ & 0.000 \\
\hline INR & $1.16(0.17)$ & $1.28(0.52)$ & 0.198 \\
\hline APTT/Sec & $30.36(6.16)$ & $31.07(7.21)$ & 0.606 \\
\hline $\mathrm{PT} / \mathrm{Sec}$ & $13.68(2.46)$ & $15.34(7.25)$ & 0.206 \\
\hline \multicolumn{4}{|l|}{ Electrolytes and renal profile } \\
\hline Creatinine & $1.22(0.64)$ & $0.81(0.25)$ & 0.016 \\
\hline Sodium & $146.93(10.55)$ & $140.32(5.09)$ & 0.779 \\
\hline Potassium & $4.38(0.49)$ & $4.57(0.51)$ & 0.198 \\
\hline \multicolumn{4}{|l|}{ Liver function test } \\
\hline ALT/SGPT(U/L0) & $55.39(45.20)$ & $48.60(26.04)$ & 0.388 \\
\hline T. bilirubin & $0.54(0.25)$ & $0.91(1.41)$ & $\mathbf{0 . 0 5 4}$ \\
\hline \multicolumn{4}{|l|}{ Inflammatory Markers } \\
\hline CRP & $82.85(44.52)$ & $84.68(57.25)$ & 0.001 \\
\hline LDH & $619.00(257.32)$ & $587.58(178.31)$ & 0.000 \\
\hline Ferritin & $597.87(390.37)$ & $996.81(892.21)$ & $\mathbf{0 . 0 0 0}$ \\
\hline Procalcitonin & $0.21(0.19)$ & $2.79(5.96)$ & 0.093 \\
\hline ESR & $30.67(11.59)$ & $48.67(29.87)$ & 0.681 \\
\hline \multicolumn{4}{|l|}{ Other } \\
\hline Troponin & $11.27(21.98)$ & 78.38(180.36) & 0.154 \\
\hline $\begin{array}{l}\text { Hospital Duration (Number } \\
\text { of Days) }\end{array}$ & $5.89(3.41)$ & $10.79(7.00)$ & 0.000 \\
\hline
\end{tabular}

Data are mean (S.D.)

$P$ values suggest the disparity between mild/moderate and severe COVID-19 patients. Significance level for $p$ value $\leq 0.050$. 
medRxiv preprint doi: https://doi.org/10.1101/2021.09.25.21264111; this version posted September 27, 2021. The copyright holder for this preprint (which was not certified by peer review) is the author/funder, who has granted medRxiv a license to display the preprint in perpetuity.

It is made available under a CC-BY-NC-ND 4.0 International license .

Table 5 Treatment of 452 symptomatic COVID-19 Patients

\begin{tabular}{|l|l|l|l|l|}
\hline Treatment & Total $(\mathbf{n = 4 5 2})$ & $\begin{array}{l}\text { Mild/Moderate } \\
(\mathbf{n = 2 3 9})\end{array}$ & $\begin{array}{l}\text { Severe } \\
(\mathbf{n = 2 1 3})\end{array}$ & P value \\
\hline Dexamethasone & $418(92.5)$ & $207(86.6)$ & $211(99)$ & $\mathbf{0 . 0 0 0}$ \\
\hline Remdesivir & $314(69.4)$ & $136(56.9)$ & $178(83.5)$ & $\mathbf{0 . 0 0 0}$ \\
\hline Azithromycin & $206(45.6)$ & $119(49.8)$ & $87(40.8)$ & 0.059 \\
\hline Meropenem & $197(43.6)$ & $76(31.8)$ & $121(56.8)$ & $\mathbf{0 . 0 0 0}$ \\
\hline Clexane & $192(42.5)$ & $100(41.8)$ & $92(43.2)$ & 0.776 \\
\hline Heparin & $187(41.4)$ & $75(31.4)$ & $112(52.6)$ & $\mathbf{0 . 0 0 0}$ \\
\hline Fluoroquinolones & $152(33.6)$ & $87(36.4)$ & $65(30.5)$ & 0.196 \\
\hline Tocilizumab & $15(3.3)$ & $1(0.42)$ & $14(6.6)$ & $\mathbf{0 . 0 0 0}$ \\
\hline
\end{tabular}

Data are $\mathrm{n}(\%)$

$\mathrm{P}$ values suggest the disparity between mild/moderate and severe COVID-19 patients. Significance level for $p$ value $\leq 0.050$. 
Table 6 Principal Component Analysis of Laboratory Parameters.

\begin{tabular}{|c|c|c|c|c|c|c|c|c|c|c|c|c|c|c|c|c|c|}
\hline Lymphocytes & 1.000 & & & & & & & & & & & & & & & & \\
\hline Neutrophils & 0.004 & 1.000 & & & & & & & & & & & & & & & \\
\hline Ferritin & $-.176^{* * *}$ & $.332^{* * *}$ & 1.000 & & & & & & & & & & & & & & \\
\hline D-Dimer & -0.056 & $.295^{* *}$ & $.295^{* * *}$ & 1.000 & & & & & & & & & & & & & \\
\hline Troponin & $.372^{*}$ & 0.099 & 0.181 & 0.074 & 1.000 & & & & & & & & & & & & \\
\hline $\mathrm{LDH}$ & -0.026 & $.274^{* *}$ & $.361^{* * *}$ & $.402^{* *}$ & -0.162 & 1.000 & & & & & & & & & & & \\
\hline CRP & -0.086 & $.216{ }^{* * *}$ & $.302^{* * *}$ & $.143^{*}$ & 0.048 & $.267^{\text {*** }}$ & 1.000 & & & & & & & & & & \\
\hline Procalcitonin & -0.098 & -0.020 & 0.250 & $.348^{* * *}$ & 0.155 & -0.122 & $.415^{* *}$ & 1.000 & & & & & & & & & \\
\hline Potassium & 0.066 & 0.020 & 0.011 & $.133^{*}$ & 0.067 & 0.005 & $-.138^{*}$ & -0.109 & 1.000 & & & & & & & & \\
\hline Sodium & 0.051 & 0.079 & 0.009 & 0.039 & 0.121 & 0.135 & -0.078 & -0.076 & -0.021 & 1.000 & & & & & & & \\
\hline T. bilirubin & -0.079 & $.152^{*}$ & $.216^{* * *}$ & $.153^{*}$ & -0.274 & 0.086 & -0.021 & 0.110 & -0.111 & -0.039 & 1.000 & & & & & & \\
\hline ALT/SGPT & 0.050 & 0.074 & $.175^{* *}$ & 0.091 & -0.195 & $.180^{*}$ & -0.080 & -0.151 & 0.027 & 0.029 & $.134^{*}$ & 1.000 & & & & & \\
\hline INR & 0.065 & $.249^{* * *}$ & 0.133 & $.231^{* * *}$ & -0.198 & -0.097 & -0.108 & 0.163 & 0.065 & 0.055 & 0.141 & 0.003 & 1.000 & & & & \\
\hline Platelets & 0.053 & 0.004 & -0.064 & $\begin{array}{r}- \\
0.086\end{array}$ & 0.234 & -0.006 & -0.008 & 0.005 & 0.052 & $-.172^{* * *}$ & $-.171^{* *}$ & -0.034 & 0.037 & 1.000 & & & \\
\hline Haematocrit & -0.089 & 0.035 & $.134^{*}$ & 0.031 & -0.201 & 0.151 & -0.096 & -0.187 & 0.053 & -0.065 & 0.119 & $.287^{* * *}$ & 0.126 & 0.038 & 1.000 & & \\
\hline WBC & $.116 *$ & $.748^{* * *}$ & $.225^{* *}$ & $.342^{* *}$ & 0.171 & $.311^{* * *}$ & $.183^{* * *}$ & 0.043 & -0.009 & 0.111 & 0.107 & 0.079 & $.243_{*}^{*}$ & 0.052 & 0.092 & 1.000 & \\
\hline $\mathrm{Hb}$ & -0.067 & 0.020 & $.175^{* *}$ & $\begin{array}{r}- \\
0.080\end{array}$ & -0.164 & 0.099 & $-.117^{*}$ & -0.245 & 0.080 & $-.128^{*}$ & $.137^{*}$ & $.298^{* * *}$ & 0.080 & -0.008 & $.855^{* *}$ & 0.023 & 1.000 \\
\hline $\begin{array}{c}\text { Laboratory } \\
\text { variable }\end{array}$ & $\begin{array}{l}\text { Lymph } \\
\text { ocytes }\end{array}$ & $\begin{array}{l}\text { Neuro } \\
\text { phils }\end{array}$ & Ferritin & $\begin{array}{c}\text { D- } \\
\text { Dimer }\end{array}$ & $\begin{array}{c}\text { Tropo } \\
\text { nin }\end{array}$ & LDH & CRP & $\begin{array}{l}\text { Procalci } \\
\text { tonin }\end{array}$ & $\begin{array}{l}\text { Potassi } \\
\text { um }\end{array}$ & Sodium & $\begin{array}{c}\mathrm{T} . \\
\text { bilirub } \\
\text { in }\end{array}$ & $\begin{array}{c}\text { ALT/S } \\
\text { GPT }\end{array}$ & INR & $\begin{array}{c}\text { Platel } \\
\text { ets }\end{array}$ & $\begin{array}{c}\text { Haem } \\
\text { atocri } \\
\mathrm{t}\end{array}$ & WBC & $\mathrm{Hb}$ \\
\hline
\end{tabular}

Correlation is significant at the 0.01 level (2-tailed).

*Correlation is significant at the 0.05 level (2-tailed). 


\section{Table 7 Findings of CT Scan of 30 COVID-19 Patients}

\begin{tabular}{|c|c|c|c|c|c|c|c|}
\hline \multirow[t]{2}{*}{ Findings } & \multirow{2}{*}{$\begin{array}{l}\text { Number of } \\
\text { Patients } \\
n=30\end{array}$} & \multicolumn{2}{|c|}{ Age } & \multicolumn{2}{|c|}{ Gender } & \multicolumn{2}{|c|}{ Severity } \\
\hline & & $\leq 50(\mathrm{n}=6)$ & $>50(n=24)$ & Male $(n=23)$ & $\begin{array}{l}\text { Female } \\
(\mathrm{n}=7)\end{array}$ & $\begin{array}{l}\text { Mild/Moderate } \\
(\mathrm{n}=7)\end{array}$ & $\begin{array}{l}\text { Severe } \\
(\mathrm{n}=23)\end{array}$ \\
\hline Consolidation & $1(3.3)$ & & $1(4.2)$ & $1(4.3)$ & & & $1(4.3)$ \\
\hline Cavities & $1(3.3)$ & & $1(4.2)$ & $1(4.3)$ & & & $1(4.3)$ \\
\hline $\begin{array}{l}\text { GGO and } \\
\text { Consolidation }\end{array}$ & $12(40)$ & $3(50)$ & $9(37.5)$ & $10(43.5)$ & $2(28.5)$ & $2(28.5)$ & $10(43.5)$ \\
\hline GGO and Opacities & $2(6.7)$ & & $2(8.3)$ & $1(4.3)$ & $1(14.2)$ & & $2(8.7)$ \\
\hline Infiltration & $2(6.7)$ & & $2(8.3)$ & $2(8.7)$ & & & $2(8.7)$ \\
\hline GGO & $28(93.3)$ & $6(100)$ & $22(91.7)$ & $21(91.3)$ & $7(100)$ & $6(85.7)$ & $22(95.6)$ \\
\hline GGO and Nodule & $1(3.3)$ & $1(16.7)$ & & $1(4.3)$ & & & $1(4.3)$ \\
\hline $\begin{array}{l}\text { Interlobular septal } \\
\text { thickening }\end{array}$ & $6(20)$ & $3(50)$ & $3(12.5)$ & $4(17.4)$ & $2(28.5)$ & & $6(26.1)$ \\
\hline $\begin{array}{l}\text { Lobes Involved }(0-5) \\
n=30\end{array}$ & $30(100)$ & $6(100)$ & $24(100)$ & $23(100)$ & $7(100)$ & $7(100)$ & $23(100)$ \\
\hline One Lobe & $1(3.3)$ & & $1(4.7)$ & $1(4.3)$ & & & $1(4.3)$ \\
\hline Two Lobes & $2(6.7)$ & & $2(8.3)$ & $2(8.7)$ & & & $2(8.7)$ \\
\hline Three Lobes & $2(6.7)$ & & $2(8.3)$ & $2(8.7)$ & & $1(14.3)$ & $1(4.3)$ \\
\hline Four Lobes & $8(26.7)$ & $1(16.7)$ & $7(29.2)$ & $8(34.8)$ & & $3(42.8)$ & $5(21.7)$ \\
\hline Five Lobes & $17(57.7)$ & $5(83.3)$ & $12(50)$ & $10(43.5)$ & $7(100)$ & $3(42.8)$ & $14(60.8)$ \\
\hline $\begin{array}{l}\text { \% age of lung } \\
\text { involvement } n(\%), \\
\text { Mean (SD) }\end{array}$ & $30(100)$ & $\begin{array}{l}6(100) \\
42.5(17.2)\end{array}$ & $\begin{array}{l}24(100), \\
54.4(14.1)\end{array}$ & $\begin{array}{l}23(100), \\
51.3(15.8)\end{array}$ & $\begin{array}{l}7(100), \\
54.3(14.3)\end{array}$ & $\begin{array}{l}7(100), \\
44.3(12.7)\end{array}$ & $\begin{array}{l}23(100), \\
54.3(15.4)\end{array}$ \\
\hline
\end{tabular}

Data are $\mathrm{n}(\%)$ and mean (S.D.) 


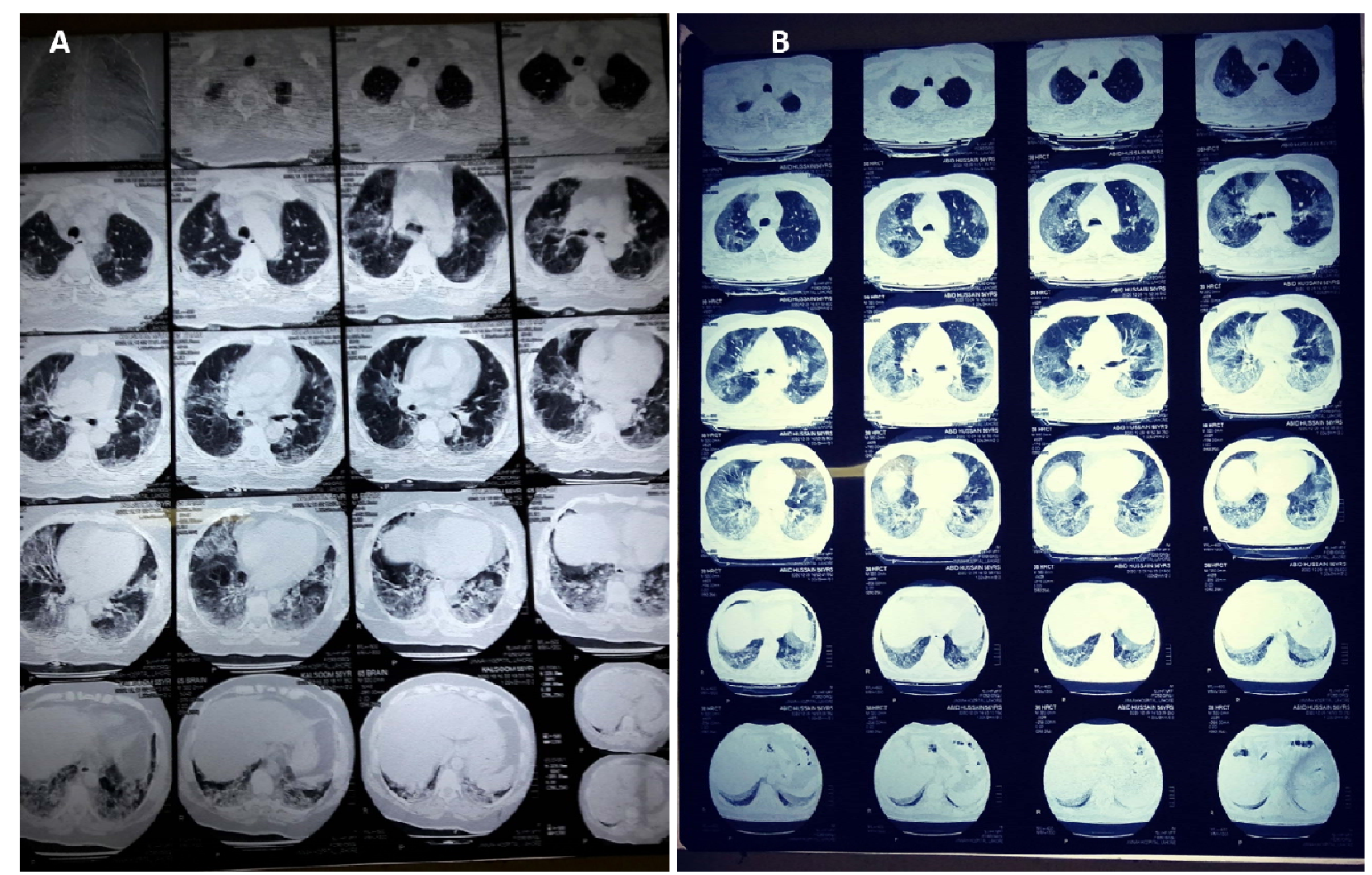

Figure 2: CT scan digital images of (A) mild to moderate and (B) Sever SARS-CoV-2 infected patients. The percentage of lungs involvement cab be spotted significantly in both patients. 